\title{
A Cap-and-Trade Model of International Trade
}

\author{
Monica Das (Corresponding author) \\ Department of Economics, Skidmore College \\ 815 N Broadway, Saratoga Springs, New York 12866, USA \\ Tel: 1- 518-580-5096Ｅ-mail: mdas@skidmore.edu \\ Sandwip Kumar Das \\ Economics Department, State University of New York \\ 1400 Washington Avenue, Albany, New York 12222, USA \\ Tel: 1-518-442-3300 E-mail: SD612629@albany.edu
}

$\begin{array}{ll}\text { Received: December 19, } 2011 & \text { Accepted: February 15, } 2012 \quad \text { Published: June 1, } 2012 \\ \text { doi:10.5539/res.v4n2p2 } & \text { URL: http://dx.doi.org/10.5539/res.v4n2p2 }\end{array}$

\begin{abstract}
The paper introduces one variant of cap-and-trade system of environmental policy and shows its effects on income distribution, structure of production and comparative advantage. The main result is that cap-and-trade leaves no scope to dispute the pollution haven hypothesis. A country may certainly make discretionary use of cap-and-trade parameters to improve its competitiveness in world trade. An expansion of the supply of permits may turn out to be a new trade policy, making a mockery of the objective of reversing climate change. This paper underscores the importance of free international trading in permits.
\end{abstract}

Keywords: Pollution haven hypothesis, Cap-and-trade, Two-sector general equilibrium, Comparative advantage

\section{Introduction}

The current controversy related to the effectiveness of the cap-and-trade system of environmental policies in controlling pollution and global warming provides the motivation behind this paper. The concept of setting caps on pollution and then allowing the industries to trade pollution rights has lately become popular among environmentalists and governments. Thomas Crocker (Note 1), who first conceived the idea, is now skeptical of the cap-and-trade legislation that is working its way through United States Congress. Crocker's skepticism is not without a foundation. A pollution tax seems a lot simpler to implement. But since pollution tax is related to the source of pollution, like a gasoline tax, Stavins (1998) argues that its purpose is primarily to raise revenue rather than reduce pollution. Europe's experiment with cap-and-trade was not very encouraging in the beginning because the industries were granted more permits than they needed, resulting in an increase in emissions. Developing countries like India and China are of the view that cap-and-trade would curb the rate of economic growth. The refusal of India and China to go along with the carbon-dioxide limits proposed in the recent G-8 meeting may turn out to be an argument against the cap and trade bill currently being considered by the Senate (Note 2). However, some developing countries are making long-term plans to implement the European model of cap-and-trade. The Indian government is setting up energy benchmarks for each industry sector and the companies exceeding the benchmark would have to buy energy certificates from those using less energy due to energy efficient practices (Note 3). It appears that the world is heading towards country-specific models of cap-and-trade to reduce emissions with no sign of an international agreement.

The theoretical literature favors pollution tax and tradable permits and shows that a well-designed pollution tax may serve the same purpose as a permit system in controlling pollution (Crocker, 1966; Dales, 1968; Montgomery, 1972). These policies can be designed to minimize the cost of achieving a target of pollution abatement (Baumol and Oates, 1988) as well as to provide incentives for development of better pollution control technologies (Milliman and Prince, 1989). As Stavins (1998) mentions, currently most countries try to protect 
the environment by command-and-control type regulations, requiring the firms to spend money on abatement, rather than depend on market oriented instruments like pollution tax or tradable permits. There is no uniformity in command-and-control policies across countries. If every country designs its own cap-and-trade model to regulate environmental damage without an international agreement to reverse climate change, then the question that should be asked is whether cap-and-trade would be any different from the currently followed environmental policies.

While an efficient environmental policy is an important issue, the trade and environment literature has focused on a broader issue, namely the effect of an environmental policy on pattern of specialization and trade among nations. The main debate is related to the question whether a stricter environmental policy would change a country's structure of production and comparative advantage and the pollution haven hypothesis (PHH) is at the center of this debate. According to this hypothesis, if U.S. follows a more stringent environmental policy to reduce pollution, some industries may become less competitive in the world market resulting in a decline in U.S. exports and some industries may even relocate to other countries where environmental policy is less stringent. There are theoretical arguments both for and against this hypothesis. Copeland and Taylor $(1994,1997)$ prove that higher pollution taxes can reduce a country's comparative advantage in the polluting industry. However, Chua (2003) shows how higher environmental taxes may not affect a country's comparative advantage in the dirty industry. Das and Das (2007), show that the PHH may not be valid in a model with command and control (CAC) programs of regulation (Note 4). Copeland and Taylor (1995), Rauscher (1997) and McAusland (2003) arrive at similar conclusions when pollution is a by-product of consumption rather than production of dirty goods. Moreover, the empirical evidence on the PHH is inconclusive (Tobey (1990), Liddle (2001), and Copeland and Taylor (2004)), since besides the environmental standards; other factors like factor endowments also influence the pattern of trade and specialization (Note 5).

A pollution tax or command-and-control regulation on a polluting industry raises its costs. In a standard general equilibrium trade model, this leads to adjustments in the factor markets. For instance, a tax or a higher abatement norm raises the average cost of the polluting firms and the competitive mechanism works to reduce the real rewards of the factor intensively used in the polluting industry. For instance, the initial disadvantage created by the tax or the abatement norm for a capital intensive industry may be offset by a decrease in the real rental on capital. A developing country, planning to be a pollution haven, may reduce the pollution tax rate or do away with abatement requirements which would reduce the average cost of its polluting industry. If this industry is labor intensive, the factor market adjustments would raise the real wages, offsetting the initial advantage created for the country's labor intensive export industry by a regressive environmental policy. This is precisely the issue discussed in McGuire (1982), Fullerton and Heutel (2006) and Das and Das (2007) and probably one of the reasons why the empirical literature testing the PHH has come up with inconclusive results.

In models with a clean and a dirty industry, environmental policy would change the average cost of firms in the dirty industry and would have no initial impact on the clean industry before the adjustments in the factor market take place. However, the way cap-and-trade is supposed to work, trading in pollution permits would create a disadvantage for the dirty industry that would need to buy permits from the clean industry and an advantage for the clean industry that earns revenue from selling permits.

The paper has also been motivated by the fact that the implications of permit trading for income distribution, production structure and comparative advantage have not been studied yet. The crucial issue is whether permit trading would lead to adjustments in the factor markets that would act as offsetting forces and whether the PHH is valid when the environmental policy is a cap-trade-system. The number of permits issued becomes a policy variable under the control of national governments. Can a country use this variable to create pollution havens? In an empirical study, Ederington and Minier (2003) show that when environmental regulation is endogenous, its effects on trade flows is significantly higher than previously reported, which supports our concern that permit supplies can be effectively used by countries as an instrument of trade policy.

In the context of general equilibrium modeling of emission permits, Goulder et al (1999) have looked at cost-effectiveness of a wide range of environmental policy instruments including cap-and-trade in an economy producing one clean and one dirty good. In the same context, Fullerton and Metcalf (2001) have made an assessment of the magnitude of welfare gain or loss resulting from tradable permits, direct control on emissions, subsidies for non-polluting activities or mandated technology adoption in the presence of pre-existing distortionary taxes. Since these are one-factor models, none of these studies is equipped to address the standard trade theoretic issues related to the effect of emission trading on patterns of production or trade or factor income distribution. 
The objective of this paper is to formulate a standard trade theoretic model with two factors and two goods, assuming that the clean good sector sells emission permits to the dirty good sector. The permits are costlessly allocated to both sectors, but the polluting sector does not get enough of these permits and purchases the balance of the requirement from the clean sector. Unlike in the models involving command-and-control type regulations (such as Das and Das, 2007, 2009) or pollution tax (Chua, 2003), the effects of pollution permits on income distribution, production structure and pattern of trade are unambiguous. A country may certainly become a pollution haven by increasing the number of permits issued or by reducing the polluting industry's permit requirement. However, free international trading of permits would prohibit a country from using permit issue to manipulate comparative advantage, which underscores the need for an international agreement on the cap-and-trade system of environmental policy.

The following section introduces one version of cap-and-trade in a two-sector general equilibrium model to discuss the effects of cap-and-trade parameters on income distribution, structure of production and comparative advantage. Section 3 demonstrates that cap-and-trade necessarily leaves scope of pollution haven, unless an international agreement fixes the cap-and-trade parameters uniformly for all countries and free international trade in emission permits is allowed. The paper is concluded in section 4. Technical details are available in the appendix.

\section{The Model}

\subsection{Cap-and-Trade model in general equilibrium}

This section formulates a general equilibrium model in which a polluting industry purchases permits from a less polluting industry to satisfy the requirements of a cap-and-trade policy. There are two major cap-and-trade proposals. The first involves setting caps on total annual emissions on firms and then holding auctions where major emitters, such as utilities or refineries, buy credits for their emissions. Emitters with low emission intensity of production can sell any extra credits they may have purchased. The second is cap-and-trade with grandfathered credits. Under this system, the government sets a cap on total annual emissions and allocates emission credits for free to emitters based on their historical or expected emissions. The credits can be used by the owner or sold to other emitters. However, many of the current proposals are a hybrid, as pointed out by Durning et al (2009). We have assumed cap-and-trade with a grandfathering provision under which both the cap and the allocated permits are proportional to the currently produced output of the industry. The cap for the industry that is known for excessive emissions is set at a higher level than the cap on a relatively clean industry. The allocation principle works in the reverse direction which means that the permits allocated to polluting industry in proportion to output are smaller than those going to the clean industry.

Let $X_{1}$ and $X_{2}$ be the current levels of production in two industries whose pollution indexes are $\rho_{1}$ and $\rho_{2}$, with $\rho_{1}>\rho_{2}$, indicating that the first industry is more pollution intensive than the second industry (where $\rho_{1}=R_{1} / X_{1}$ and $\left.\rho_{2}=R_{2} / X_{2}\right)$. The number of emission permits required, i.e. the cap, depends upon the pollution intensity and the level of production: $R_{1}=\rho_{1} X_{1}$ and $R_{2}=\rho_{2} X_{2}$, where $R_{1}$ and $R_{2}$ are the numbers of permits required by the two industries. The permits are freely allocated in proportion to the current level of production: $\bar{R}_{1}=s_{1} X_{1}$ and $\bar{R}_{2}=s_{2} X_{2}$, where $s_{1}>0$ and $s_{2}>0$ are fixed proportions. The total number of permits granted, $\bar{R}$ is fixed: $\bar{R}_{1}+\bar{R}_{2}=\bar{R}$. The total demand for permits is: $D_{P}=R_{1}+R_{2}$. The permit demand function is derived from the profit maximizing behavior of the producers in the two industries. An increase in the price of permits, relative to the price of the second industry would raise the permit cost of the pollution intensive industry, which will produce less and therefore demand less permits. On the other hand, for any given permit price, an increase in the price of the pollution intensive industry relative to the price of the second industry would raise output of the pollution intensive industry, which would require more permits.

The permit demand function is: $D_{P}=G\left(P_{1} / P_{2}, P_{R} / P_{2}\right)$, where $P_{1}, P_{2}$ and $P_{R}$ are respectively the prices of the two goods and the permit price. All prices, including the factor prices that are uniquely determined by product prices, are measured by choosing the second good as the numéraire. Linearlizing the permit demand function around the equilibrium values, we get: $D_{P}=a-b\left(P_{R} / P_{2}\right)+c\left(P_{1} / P_{2}\right), a>0, b>0, c>0$. The permit market is in equilibrium when $D_{P}=\bar{R}$, where $\bar{R}$ is the supply of permits. The permit price in equilibrium is: $P_{R}^{e} / P_{2}=\alpha+\beta\left(P_{1} / P_{2}\right)-\gamma \bar{R}(\alpha \equiv a / b>0, \beta \equiv c / b>0, \gamma \equiv 1 / b>0)$. The permit costs are $P_{R}^{e}\left(\rho_{1}-s_{1}\right) X_{1}$ and $P_{R}^{e}\left(\rho_{2}-s_{2}\right) X_{2}$ for the two industries respectively. While this is a positive cost for the first industry whose pollution intensity is high relative to the second industry, the permit cost for the second industry is negative and it represents the revenue it receives from sale of excess credits. It is assumed that $s_{2}>\rho_{2}>0$ and $\rho_{1}>s_{1}>0$, as the second industry is less polluting than the first industry and therefore it has more permits than needed. Since both the cap and the allocated permits are proportional to the current level of production, this system of 
administering the permit system creates a divergence between the price the consumers pay for the goods produced and the price the producers receive. Let $P_{1}$ and $P_{2}$ be the prices paid by the consumers. Then the net prices received by the producers per unit of output sold are:

$$
\begin{aligned}
& P_{1}^{\prime}=P_{1}-P_{R}^{e}\left(\rho_{1}-s_{1}\right) \\
& P_{2}^{\prime}=P_{2}+P_{R}^{e}\left(s_{2}-\rho_{2}\right)
\end{aligned}
$$

For the polluting industry, $P_{R}^{e}\left(\rho_{1}-s_{1}\right)$ is the cost of permits per unit of output produced and sold and for the clean industry, $P_{R}^{e}\left(s_{2}-\rho_{2}\right)$ is like a subsidy per unit of output sold, as this is what it is earned by selling permits. Since the total permit cost for the polluting industry is $P_{R}^{e}\left(\rho_{1}-s_{1}\right) X_{1}$ and the total revenue from permit sale by the clean industry is $P_{R}^{e}\left(s_{2}-\rho_{2}\right) X_{2}$, these must be equal: $P_{R}^{e}\left(\rho_{1}-s_{1}\right) X_{1}=P_{R}^{e}\left(s_{2}-\rho_{2}\right) X_{2}$. Then (2.1) and (2.2) imply that $P_{1}^{\prime} X_{1}+P_{2}^{\prime} X_{2}=P_{1} X_{1}+P_{2} X_{2}$. In figure $1, \mathrm{P}$ represents given quantities of $X_{1}$ and $X_{2}$ produced, line $\mathrm{AB}$ represents the value of these quantities at producer prices, and line $\mathrm{CD}$ represents their value at consumer prices. Then, AC is the cost of permits paid by the producers of the polluting good, measured in units of the polluting good, and BD is the revenue from permit sale, measured in units of the clean good, that accrues to the producers of the clean good.

The rest of the model takes the form of the standard two-sector general equilibrium model with two good and two factors, labor and capital. The markets for goods and factors of production are assumed to be perfectly competitive and the factors are fully employed. Production of each good requires two factors of production, labor and capital, with the technology characterized by constant returns to scale. The emission permits are not inputs in production. They simply perform an enabling function; as production involves pollution, permits are required to produce and pollute.

The profit functions of the two industries are:

$$
\begin{gathered}
\Pi_{1}=P_{1}^{\prime} F_{1}\left(L_{1}, K_{1}\right)-w L_{1}-r K_{1} \\
\Pi_{2}=P_{2}^{\prime} F_{2}\left(L_{2}, K_{2}\right)-w L_{2}-r K_{2}
\end{gathered}
$$

$L_{i}$ and $K_{i}$ are respectively the labor and capital inputs employed in industry $i, w$ and $r$ are the wage rate and capital's rental and $X_{i}=F_{i}\left(L_{i}, K_{i}\right)$ are the production functions $(i=1,2)$, assumed to be homogenous of degree one. Profits are maximized by equating the value of the marginal productivity of a factor with its price: $P_{i}^{\prime} F_{L i}\left(L_{i}, K_{i}\right)=w$ and $P_{i}^{\prime} F_{K i}\left(L_{i}, K_{i}\right)=r$, which, by the homogeneity property of the production functions, would mean that in equilibrium, the industry profits $\Pi_{1}=\Pi_{2}=0$. Applying the zero profit condition in (2.3) and (2.4) and dividing these equations by $X_{1}$ and $X_{2}$ respectively,

$$
\begin{gathered}
w C_{L 1}+r C_{K 1}=P_{1}^{\prime} \\
w C_{L 2}+r C_{K 2}=P_{2}^{\prime}
\end{gathered}
$$

The input output coefficients $C_{i j}(i=L, K ; j=1,2)$ represent the quantity of labor or capital used per unit of good $j$. Due to the assumption of constant returns to scale, the values of $C_{i j}$ are uniquely determined by $\omega \equiv w / r$, as the firms minimize the factor cost of producing any given output.

$$
C_{i j}=C_{i j}(\omega) ;(i=L, K ; j=1,2)
$$

With $L$ and $K$ representing the fixed supplies of labor and capital, the full employment conditions are expressed as,

$$
\begin{aligned}
& C_{L 1} X_{1}+C_{L 2} X_{2}=L \\
& C_{K 1} X_{1}+C_{K 2} X_{2}=K
\end{aligned}
$$

This completes the supply side of the model. Given the product prices, $P_{1}$ and $P_{2}$, and the cap-and-trade parameters in (2.1) and (2.2), equations (2.5) through (2.9) would uniquely determine outputs $\left(X_{I}\right.$ and $\left.X_{2}\right)$, factor prices ( $w$ and $r$ ) and four input output coefficients $C_{i j}$. Without the cap-and-trade provisions, $P_{j}=P_{j}^{\prime}$ in $(2.1)$ and (2.2) and the model reduces to the standard model.

The demand side is modeled by a social utility function that exhibits a constant elasticity of substitution between the dirty and clean goods, along with $\mu$, a shift parameter representing the society's environmental awareness, which produces a bias in favor of the clean good. This creates the possibility of government's environmental policy strengthening the consumers' preference for the clean good. Let $U\left(D_{1}, D_{2}\right)$ be the social utility function, where $D_{1}$ and $D_{2}$ represent the quantities of the polluting and clean goods demanded respectively.

$$
\begin{aligned}
& U\left(D_{1}, D_{2}\right)=D_{1}^{\alpha}+\left(\mu D_{2}\right)^{\alpha} \\
& (0<\alpha<1 ; \quad \mu>0)
\end{aligned}
$$


The elasticity of substitution, $\sigma_{D} \equiv 1 /(1-\alpha)>0$, is a constant. The demand functions are derived by maximizing (2.10) subject to the budget constraint: $Y=P_{1} D_{1}+P_{2} D_{2}$, where $\mathrm{Y}$ is income, and these are: $D_{1}=\left[\mu^{\alpha /(1-\alpha)} P_{1}^{1 /(\alpha-1)} Y\right] / Z$ and $D_{2}=\left[P_{2}^{1 /(\alpha-1)} Y\right] / Z$, where $Z \equiv \mu^{\alpha /(\alpha-1)} P_{1}^{\alpha /(\alpha-1)}+P_{2}^{\alpha /(\alpha-1)}$. The ratio between $D_{1}$ and $D_{2}$ is

$$
D_{1} / D_{2}=\mu^{\frac{\alpha}{\alpha-1}}\left[P_{1} / P_{2}\right]^{\frac{1}{\alpha-1}}
$$

In the autarky equilibrium, $D_{1} / D_{2}=X_{1} / X_{2}$, which is used in (2.11) to determine the equilibrium terms of trade in the closed economy.

\subsection{Permit trading and income distribution}

The producer prices in equations (2.5) and (2.6) would change whenever there is any change in the parameters of the cap-and-trade policy. These parameters are: number of permits issued $(\bar{R})$, the cap on the polluting industry $\left(\rho_{1}\right)$ and the permit allocation parameters, $s_{1}$ and $s_{2}$. For the same of simplicity, we assume that the cap on the second industry is held constant. Let us suppose that the number of permits issued decreases, as the environmental policy becomes stricter. This would raise the equilibrium price of permits, raising the permit cost of the first industry and the revenue from the permit sale for the second industry, per unit of their respective outputs. The zero-profit equilibrium represented by equations (2.5) and (2.6) is disturbed which is corrected by subsequent adjustments in the factor markets. These adjustments would be to reduce average production cost in industry 1 and to increase it in industry 2, to restore the zero profit equilibrium. These adjustments are shown in figure 2, where it is assumed that the first industry is capital intensive relative to the second industry. $A C_{1}$ and $A C_{2}$ are the factor price frontiers of the two industries when they are earning zero profits. Due to cost minimization the slope of $A C_{1}$ measures capital labor ratio in the first industry and the slope of $A C_{2}$ measures the capital labor ratio in the second industry. This follows from equations (A.1) and (A.2) in the appendix where $P_{j}^{\prime *}=0$, before any change in the cap-and-trade parameters. After the permit price goes up, $A C_{1}$ shifts to the left, shown by $A C_{1}^{*}$, and $A C_{2}$ shifts to the right and becomes $A C_{2}^{*}$. The two rays drawn from the origin clearly show an increase in the wage rental ratio that results from the adjustments in the factor markets. Since the polluting industry is capital intensive, a decrease in its average production cost can be achieved by raising the price of its intensive factor relatively to the price of its unintensive factor. These changes in the factor prices are reinforced when the average production cost of the second industry, which is labor intensive, is raised to restore zero profit equilibrium. If the polluting industry is labor intensive, the factor price frontiers in figure 2 would be different. $A C_{2}$ is now steeper than $A C_{1}$ and a positive shift $A C_{2}$ with a negative shift of $A C_{1}$ results in a decrease in the wage rental ratio. The important point of this diagram is that there is no ambiguity in the effect of cap-and-trade parameters on income distribution, while such ambiguity is the essence of the results in some studies on command- and- control type environmental regulation. Das and Das(2007) has a diagram, similar to figure 2, where the effect of a stricter environmental norm on income distribution may be indeterminate. In Das and Das (2009), it is assumed that the environmental policy is distribution neutral.

The supply of permits is the only parameter that affects the factor price frontiers of both industries. An increase in the cap $\left(\rho_{1}\right)$ on the polluting industry or a decrease in the of permit allocation ratio for the polluting industry $\left(s_{1}\right)$ would not affect the price of permits but would raise its permit cost, as the industry would have to purchase more permits. In this case only $A C_{1}$ shifts to the left but $A C_{2}$ does not shift. The effect on the wage rental ratio is the same, i.e., it increases if the polluting industry is capital intensive. If more permits are allocated to the clean industry (an increase in $s_{2}$ ), it is able to sell more permits at a constant price. In this case $A C_{1}$ does not shift, but $A C_{2}$ shifts to the right, raising the wage rental ratio, provided that the polluting industry is capital intensive (Note6). Proposition 1 summarizes these results.

\section{Proposition 1}

A decrease in the supply of permits raises the price at which permits are traded. This would raise the permit cost per unit of output for the polluting industry and increase the revenue from permit sale per unit of output for the clean industry. The subsequent adjustments in the factor markets would raise the wage rental ratio, if the polluting industry is capital intensive and would reduce it if the polluting industry is labor intensive. The effect of an increase in the cap, a decrease in permit allocation ratio for the polluting industry or an increase in the permit allocation ratio for the clean industry on the wage rental ratio is qualitatively the same as that of a reduction of permit supply. 


\subsection{Permit trading and production structure}

The next step is to explore the effect of a change in the number of permits issued on the outputs produced by the two industries. An increase in the wage rental ratio results in a substitution of capital for labor in both industries. In figure 2, each industry shifts to a point on the upper part of the factor price frontier where the curve is steeper. Equations (A.5) and (A.6) in the appendix show that more capital and less labor is used per unit of output produced in each industry. The effect of this substitution on outputs, at constant terms of trade, is shown in figure 3, where the length of the Edgeworth box measures the supply of labor and its height measures the supply of capital in the economy. The rays drawn from the upper right hand corner of the box represent output of the first industry and those drawn from the lower left hand corner represent output of the second industry.

Point $\mathrm{P}$ is the initial production equilibrium in a fully employed economy, with the lengths of $O^{\prime} P$ and $O P$ representing the outputs $X_{1}$ and $X_{2}$. The fact that $\mathrm{P}$ is below the diagonal of the box $\left(O O^{\prime}\right)$ indicates that the first industry is capital intensive. At constant terms of trade, a decrease in the number of permits raises the capital labor ratios in both industries and this change is shown in the diagram when the production equilibrium shifts to point $\mathrm{Q}$, indicating that $X_{1}$ decreases (from $O^{\prime} P$ to $O^{\prime} Q$ ) and $X_{2}$ increases (from $O P$ to $O Q$ ). The structure of production, that is represented by the ratio, $X_{1} / X_{2}$, decreases. The formal proof of this result is in equation (A.9) in the appendix. The effect does not depend on which sector is capital intensive. If the polluting good is labor intensive, $A C_{2}$ curve in figure 2 will be steeper than $A C_{1}$ curve. As the number of permits issued is reduced, $A C_{1}$ shifts to the left and $A C_{2}$ shifts to the right. But, in this case, the wage rental ratio will decrease, lowering the capital labor ratios in both industries. In figure 3 , the production equilibrium points will now be above the diagonal and the rays drawn will show a decrease in $X_{1} / X_{2}$ (Note 7).The effects of changes in the other cap-and-trade parameters on the structure of production are similar to the effect of a decrease in the supply of permits. A decrease in $\rho_{1}$ or $s_{1}$, or an increase in $s_{2}$ would also reduce $X_{1}$ relative to $X_{2}$. Though these effects are qualitatively the same as the effect of a change in the permit supply, their magnitudes would be somewhat smaller. The reason is that a change in any one of these parameters would shift only one of the factor price frontiers, not both, as in the case of a change in permit supply. Therefore, the amount of change in the wage rental ratio and resulting change in the capital labor ratios would be smaller. Proposition 2 has the summary of these results.

\section{Proposition 2}

At constant terms of trade, a decrease in the supply of permits results in a decrease in the output of the polluting industry, relative to that of the clean industry, irrespective of whether the polluting industry is capital intensive or labor intensive. An increase in the cap, a decrease in the permit allocation ratio for the polluting industry or an increase in the permit allocation ratio for the clean industry would have a similar effect on the output ratio.

\subsection{Autarky equilibrium}

The firms in the two industries maximize profits by equating the value of the marginal productivity of a factor, taken at producers' prices, with the market price of the factor. This implies that the marginal rate of transformation is equated with the producers' price ratio. The point $S$ in figure 4 is the autarky equilibrium point before cap-and-trade is in force, showing equality between the marginal rate of transformation and the consumers' marginal rate of substitution (measured by the slope of the social indifference curve $U_{1}$ ) between the two goods. The slope of line $\mathrm{AB}$ represents the equilibrium terms of trade. Before cap-and-trade, there is no difference between the producers' price ratio and the consumers' price ratio. The production point shifts from $\mathrm{S}$ to $\mathrm{P}$ after the introduction of cap-and-trade. Now the producers' price ratio is the slope of the tangent drawn at $\mathrm{P}$ on the transformation curve, showing a decrease in the net price received the polluting industry and an increase in the net price received by the clean industry. An introduction of cap-and-trade results in an excess supply in the market for the clean good and an excess demand in the market for the polluting good. After the adjustments in the product markets, the new autarky equilibrium point is $\mathrm{S}^{*}$, where the consumers' price ration is represented by the slope of $\mathrm{CD}$, and the producers' price ratio is represented by the slope of the transformation curve at $\mathrm{S}^{*}$. The tangent on the transformation curve at $\mathrm{S}^{*}$ (not drawn) is steeper that line CD due to the fact that the clean good producers receive a price that is higher than what the consumers pay and the producers of the polluting good receive a lower price after paying for the permits. If a tangent is drawn at $S^{*}$ on the transformation curve, then the difference between the vertical intercept of the tangent and the vertical intercept of line CD would be the cost of permits, measured in terms of the polluting good. The difference in the horizontal intercepts of these lines would be the revenue from permit sale, measured in units of the clean good. However, in the process of product market adjustments, the relative consumer price of the clean good declines which is why $\mathrm{CD}$ is flatter than $\mathrm{AB}$. So far as welfare is concerned, cap-and-trade lowers it from $U_{1}$ to $U_{2}$, unless there is an improvement in the 
environmental awareness parameter $(\mu)$. The important point of this figure is that cap-and-trade raises the consumers' price ratio in favor of the polluting good. If the country is capital abundant and the polluting good is capital intensive, cap-and-trade affects comparative advantage adversely.

The autarky equilibrium point $\mathrm{S}^{*}$ in figure 4 will change if the supply of permits or other cap-and-trade parameters are altered. A simpler way to look at the results of these changes would be to invoke the relationship between the demand ratio $\left(D_{1} / D_{2}\right)$ and the terms of trade $\left(P_{1} / P_{2}\right)$ is given by equation $(2.11)$. An increase in $P_{1} / P_{2}$ results in a lower $D_{1} / D_{2}$. On the other hand, an increase in $P_{1} / P_{2}$ raises $\left(X_{1} / X_{2}\right)$ (Note 8$)$, which is the normal relationship between relative price and relative supplies of the two goods. Figure 5 has the initial equilibrium in the economy with the demand curve D and the supply curve S.

The introduction of Cap-and-trade shifts the supply curve to the left $\left(\mathrm{S}_{1}\right)$, showing a decrease in $X_{1} / X_{2}$ at constant terms of trade. This has the effect of shifting the price ratio in favor the polluting good. A decrease in the number of permits issued would further reduce the relative supply of the polluting good $\left(\mathrm{S}_{2}\right)$ and raise its relative price. The effect of a change in any one of the other cap-and-trade parameters, discussed in the preceding section would have a similar effect of the supply curve. It should however be mentioned that the effects of these supply shocks on the relative price of the polluting goods would be somewhat moderated, if there is a concurrent change in the pollution awareness parameter, $\mu$. An increase in pollution awareness would shift the demand curve D to the left, as less of the polluting good would be demanded at any terms of trade, which would moderate any increase in the relative price of the polluting goods due to a supply shock. The terms of trade in autarky represents comparative advantage and the neoclassical trade theory determines the pattern of trade between the two countries that are identical in every respect except relative factor endowments by comparing their autarky terms of trade. The following section deals with the possibility of a country raising the number of permits issued to reverse its comparative disadvantage in the polluting good, which is main concern of the pollution haven hypothesis. Proposition 3 is the summary of the results derived from figure 5.

\section{Proposition 3}

An introduction of cap-and-trade raises the relative price of the polluting good in a closed economy. A decrease in the supply of permits causes a further increase in the relative price of the polluting good. Such movements of the terms of trade in favor the polluting good may be moderated if the consumers become more averse to the polluting good by changing their preference in favor of the clean good.

\section{Cap-and-Trade and the Pollution Haven Hypothesis}

The model with the cap-and-trade provisions, developed in the paper, is the standard two-sector general equilibrium model used to discuss the Heckscher-Ohlin theorem. In the context of this model, let us assume that the Home Country $(H)$ is relatively capital abundant and the Foreign Country $(F)$ is labor abundant. They are identical in every other respect, i.e. they have the same technology for producing the polluting good or the clean good, identical cap-and-trade parameters and equal supply of permits.

The Home country with a higher supply of capital relative to the supply of labor would have a lower price of the capital intensive good relative to that of the labor intensive good in pre-trade equilibrium. The relative cost of capital would be lower in the Home country and the relative wage rate would be higher. This would create a relative cost advantage in the capital intensive industry and a relative cost disadvantage in the labor intensive industry of the Home country. The Foreign Country would have a relative cost advantage in the labor intensive good and a relative cost disadvantage in the capital intensive good. The first term of equation (A.15) in the appendix captures the Heckscher-Ohlin effect and its sign depends on factor intensities. The rest of the terms in this equation are zero in the initial situation in which the two countries have identical cap-and-trade parameters and an identical social utility function with the same environmental awareness parameter, $\mu$. We now define $P \equiv P_{1} / P_{2}$ as the relative price of the pollution intensive good, and $k \equiv K / L$ as the ratio of the supply of capital to the supply of labor. If the polluting good is capital intensive, an increase in $k$ would reduce $P$. Figure 6 shows the relationship between $k$ and $P$, which is the relative price of the polluting good. The line AB in this diagram relates factor endowment ratio with the relative price of the polluting good that is assumed to be capital intensive. The two countries, $H$ and $F$ would have the same line, i.e. AB due to the assumption that they have identical technology, preference and cap-and-trade parameters. Let the Home Country's factor endowment ratio be $k_{H}$ and let the Foreign Country's ratio be $k_{F}, k_{H}>k_{F}$ showing that $H$ is capital abundant and $F$ is labor abundant. The line $\mathrm{AB}$ then determines the autarky price ratios. The relative price the polluting good is $\mathrm{Od}$ in $H$ and $\mathrm{Oc}$ in $F$, which proves the Heckscher-Ohlin theorem. $H$ (capital abundant) will export the polluting goods which is capital intensive and $F$ (labor abundant) will export the clean good. Now, if $F$ increases the supply of permits, it will deviate from line $\mathrm{AB}$. Let us suppose that now $F$ deviates to line $F F^{\prime}$, while $H$ stays on line $\mathrm{AB}$, 
making the relative price of the polluting good (Oe) lower in $F$. This would change the pattern of specialization and trade and simply by raising the permit supply, a country may be able to convert a comparative disadvantage into an advantage. The results will qualitatively the same if $H$ reduces the supply of permits in order to follow a more stringent environmental policy, while $F$ does not change the permit supply. In this case, $F$ stays on line AB, while $H$ moves on a line to the right of line $\mathrm{AB}$, resulting in an increase in the price of the polluting good. In either case, pollution haven is created in $F$.

There are however two countervailing forces that may act against the creation of pollution haven due to discretionary application cap-and-trade policies. When $F$ raises the supply of permits and deviates from line AB towards line $F F^{\prime}$, the consumers' environmental awareness in $H$ may improve and therefore, it may also deviate from line $\mathrm{AB}$ to line $H H^{\prime}$. In this case $H$ is able to maintain its comparative advantage in the capital intensive good, because the relative price of its polluting good would be Of, which is still lower than its relative price in $F$ (Oe), after $F$ has increased the supply of permits. There is however no logical connections between the foreign country raising permit supply and the Home Country consumers becoming more environmentally conscious. Neither of the two countries would deviate from line AB, if permits are internationally traded and therefore its price is determined in the world permit market. If this two country model is generalized to a multi-country model, then one may visualize a situation in which there is free trade in permits with no country having the power to influence the world price of permits by issuing more permits. Such additional permits would simply create a temporary divergence between the domestic and foreign permit prices. Any addition to permit supply would leak out of the country, as the foreign producers would import the cheaper permits to equalize the permit prices. If the permit price in equilibrium is $P_{R}^{W}$ when there is free trade in permits, then equations (2.1) and (2.2) would change in the following way:

$$
\begin{aligned}
& P_{1}^{\prime}=P_{1}-P_{R}^{W}\left(\rho_{1}-s_{1}\right) \\
& P_{2}^{\prime}=P_{2}+P_{R}^{W}\left(s_{2}-\rho_{2}\right)
\end{aligned}
$$

Since the domestic supply of permits, $\bar{R}$ drops out of these equations, it also drops of the equation (A.15) which is the basis of the lines drawn in figure 5. The countries would still have the option to choose the values of other cap-and-trade parameters to create an advantage. However, as we have seen in section (2.4), it is the supply of permits that has a two-way effect on the costs. The other parameters affect average cost of only one of the two industries and are likely to have a much lower impact on relative price. Proposition 4 states the effects of cap-and-trade on comparative advantage.

\section{Proposition 4}

A country may certainly create a comparative cost advantage by increasing the supply of permits. Specifically, a labor abundant country, importing a capital intensive dirty good, may reduce the permit price by issuing more permits that would change its comparative cost advantage in favor of the dirty good. Thus, the supply of permits becomes a trade policy instrument, similar to tariff and effective in achieving the objective of import substitution. However, a free trade in permits would plug this loophole in cap-and-trade policy.

\section{Conclusion}

If there is ever an international agreement on climate change and global warming, it is difficult to predict what is going to be the action plan envisaged in the agreement. In spite of the initial failure of cap-and-trade system of pollution control in Europe, it is now regarded as a successful environmental policy instrument. Currently, there is tremendous pressure on United States as well as some large countries like India and China in the developing world to implement the European model. Most countries currently have either a command-and-control approach or emission taxes to address the environmental problems. The trade and environment literature shows that the effects of these policies on the structure of production, comparative advantage and trade are uncertain. The so-called pollution haven hypothesis has been disputed both in the theoretical and in the empirical studies. It has been shown that an emission tax or an environmental standard fixed by the regulator would have some unanticipated consequences in the factor markets, making its impact on production and trade indeterminate. The initial impact of an emission tax or a standard falls only on the polluting sector of the economy. In this paper we have shown that the initial impact of cap-and-trade is a two-way impact. Simultaneously, an advantage for the clean sector and a disadvantage for the polluting sector are created, which has no unanticipated consequences and which leaves no scope to dispute the pollution haven hypothesis. A country may certainly make discretionary use of cap-and-trade parameters to improve its competitiveness in world trade. Specifically, raising the supply of permits becomes a new trade policy. There is a danger that the cap-and -trade policy without an international agreement may result in a 'permit war' along the lines of 'tariff war'. In a 'permit war', countries would raise the supply of permits to make permits cheaper for the polluting sectors, making a mockery of the 
objective of reversing global warming and climate change. However, the absence of unanticipated consequences of cap-and-trade is an advantage for the global community, because this policy unambiguously results in a decrease in the output of the polluting sector and an increase in the output of the clean sector. What is required to sustain this advantage is an international agreement in which the caps and the permit allocation parameters are determined uniformly for all countries and free international permit trading is provided for. However, since this paper treats pollution as production externality, we have ignored the possibility that welfare may improve if an environmental policy controls pollution. In this case, the consumer demand shifts in favor of the goods produced by polluting industries that are subjected to cap-and-trade regulations, which may raise their prices. Such externality in consumption, which can be modeled by including pollution in the utility function, is likely to weaken the strong result that the cap-and-trade would inevitably cause pollution haven.

\section{References}

Baumol, W. J., \& Oates, W. E. (1988). The Theory of Environmental Policy. Second edition. New York: Cambridge University Press.

Chua, S. (2003). Does tighter environmental policy lead to a comparative advantage in less polluting goods?. Oxford Economic Papers, 55, 25-35. http://dx.doi.org/10.1093/oep/55.1.25

Copeland, B. R., \& Taylor, M. S. (1994). North-South trade and the environment. Quarterly Journal of Economics, 109, 755-87. http://dx.doi.org/10.2307/2118421

Copeland, B. R., \& Taylor, M. S. (1995). Trade and Environment, A Partial Synthesis. American Journal of Agricultural Economics, 77, 765-771. http://dx.doi.org/10.2307/1243249

Copeland, B. R., \& Taylor, M. S. (1997). A simple model of trade, capital mobility and the environment. NBER working paper 5898. National Bureau of Economic Research, Cambridge MA. http://dx.doi.org/10.3386/w5898

Copeland, B. R., \& Taylor, M. S. (2004). Trade, Growth and the Environment. Journal of Economic Literature, XLII, 7-71. http://dx.doi.org/10.1257/002205104773558047

Crocker, T. D. (1966). The Structuring of Atmospheric Pollution Control System. In Harold Wolozin (ed), The Economics of Air Pollution. New York: Norton.

Dales, J. H. (1968). Pollution, Property and Prices. Toronto: University of Toronto Press.

Das, M., \& Das, S. K. (2007). Can Stricter Environmental Regulations Increase Export of the Polluting Good?. The B.E. Journal of Economic Analysis \& Policy, 7(1), 26.

Das, M., \& Das, S. K. (2009). Distribution Neutral Abatement Policy in a Model of Trade and Environment. Environment and Development Economics, 4 (14), 457-472. http://dx.doi.org/10.1017/S1355770X09005191

Durning, A., Fahey, A., Eric de P., Stiffler, L., \& Williams-Derry, C. (2009). Cap and Trade 101: A Federal Climate Change Primer. Sightline Report, July 2009 edition.

Ederington, J., \& Minier, J. (2003). Is environmental policy a secondary trade barrier? An empirical analysis. Canadian Journal of Economics. Canadian Economic Association, 36(1), 137-154.

Fullerton, D., \& Gilbert, E. M. (2001). Environmental control, scarcity rent, and pre-existing distortions. Journal of Public Economics, 80, 249-267.

Fullerton, D., \& Heutel, G. (2006). The General Equilibrium Incidence of Environmental Mandates. Working Paper, Department of Economics, University of Texas at Austin. http://dx.doi.org/10.1016/S0047-2727(00)0008 7-6

Goulder, L. H., Parry, I. W. H., Robertson, C. W., Williams III, \& Dallas, B. (1999). The cost-effectiveness of alternative instruments for environmental protection in a second-best policy setting. Journal of Public Economics, 72, 329-360. http://dx.doi.org/10.1016/S0047-2727(98)00109-1

Hettige, H., Martin, P., Singh, M., \& Wheeler, D. (1995). IPPS: The Industrial Pollution Projection System. World Bank, Policy Research Dept., Environment, Infrastructure, and Agriculture Division (Washington, DC).

Hilsenrath, J. (2009). Cap-and-Trade's Unlikely Critics: Its Creators. The Wall Street Journal, August 13.

Levinson, A., \& Taylor, M. S. (2004). Unmasking the Pollution Haven Effect. NBER Working Paper No. 10629. National Bureau of Economic Research, Cambridge MA.

Liddle, B. (2001). Free Trade and the Environment-Development System. Ecological Economics, 39, 21-36. 
Markandya, A. (2005). International Trade and Sustainable Development. Paper prepared for International Conference on Environment and Development: Developing Countries Perspective. School of International Studies, Jawaharlal Nehru University, New Delhi.

McAusland, C. (2003). Trade, Politics and the Environment: Tailpipe vs Smokestack. University of California at Santa Barbara, Economics Department, Working Paper 8-03.

McGuire, M. C. (1982), Regulation, Factor rewards and International Trade. Journal of Public Economics, 17(3), 335-354.

Milliman, S. R., \& Prince, R. (1989). Firm Incentives to Promote Technological Change in Pollution Control. Journal of Environmental Economics and Management, 17, 247-265. http://dx.doi.org/10.1016/0095-0696(89)9 0019-3

Montgomery, W. D. (1972). Markets in Licenses and Efficient Pollution Control Programs. Journal of Economic Theory, 395-418. http://dx.doi.org/10.1016/0022-0531(72)90049-X

Nicita, A., \& Olarreaga, M. (2007). Trade, Production, and Protection Database, 1976-2004. The World Bank Economic Review, 21(1), 165-171. http://dx.doi.org/10.1093/wber/lh1012

Rauscher, M. (1997). International Trade, Factor Movements, and the Environment. Oxford: Clarendon Press.

Stavins, R. N. (1998). What Can We Learn from the Grand Policy Experiment? Lessons from $\mathrm{SO}_{2}$ Allowance Trading. Journal of Economic Perspectives, 2(3), 69-88. http://dx.doi.org/10.1257/jep.12.3.69

Tobey, J. A. (1990). The Effects of Domestic Environmental Policies on Patterns of World trade: An Empirical Test. KYKLOS, 43, 191-209. http://dx.doi.org/10.1111/j.1467-6435.1990.tb00207.x

\section{Notes}

Note 1. See Hilsenrath (2009) and Crocker (1966).

Note 2. See Editorial: "Killing Cap \& Trade" in The Washington Times, Friday, July 10, 2009.

Note 3. See article in Reuters India, dated August 25, 2009.

Note 4. Das and Das (2007) define CAC regulations or standards or emission caps as those policies that involve prescribed limitations on the allowable levels of emissions and the use of specified abatement techniques.

Note 5. For an excellent survey of the literature see also Markandya (2005) and Levinson and Taylor (2004).

Note 6. See equations (A.1), (A.2), (A.7) and (A.8) in the appendix.

Note 7. For a formal proof, see equation (A.12) in the appendix.

Note 8. See the text under equation (A.12) in the appendix.

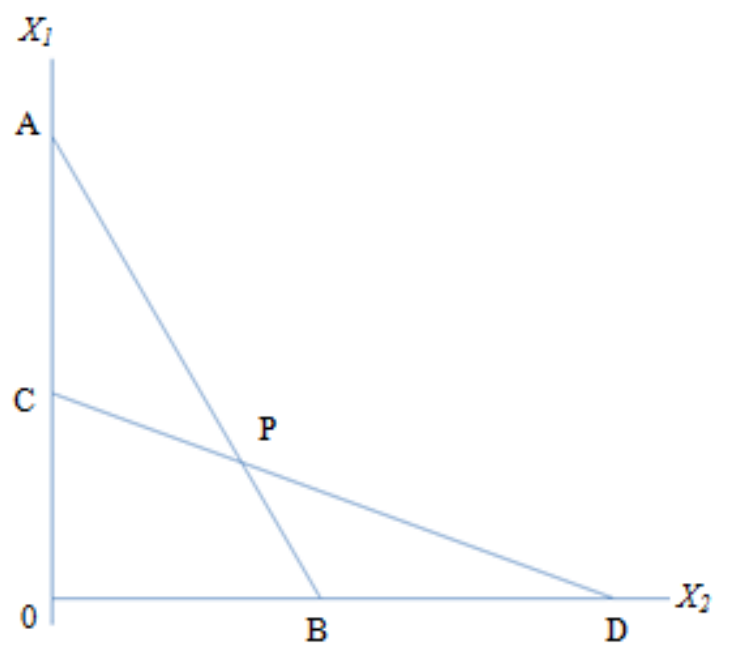

Figure 1. Permit trading 
$\mathrm{P}$ represents given quantities of $X_{1}$ and $X_{2}$ produced, line AB represents the value of these quantities at producer prices, and line CD represents their value at consumer prices. Then, AC is the cost of permits paid by the producers of the polluting good, measured in units of the polluting good, and BD is the revenue from permit sale, measured in units of the clean good, that accrues to the producers of the clean good.

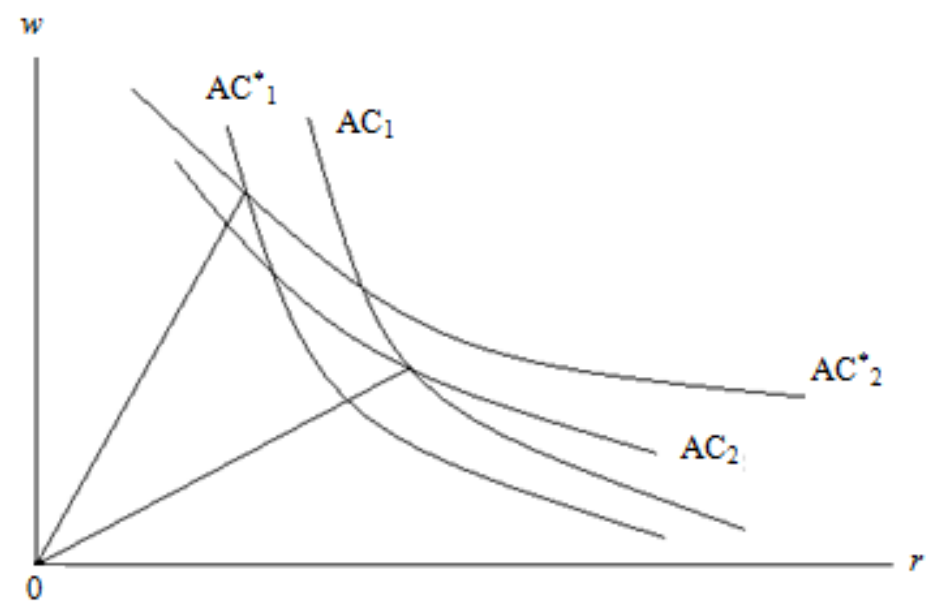

Figure 2. Income distribution

It is assumed that the first industry is capital intensive relative to the second industry. $A C_{1}$ and $A C_{2}$ are the factor price frontiers of the two industries when they are earning zero profits. Due to cost minimization the slope of $A C_{1}$ measures capital labor ratio in the first industry and the slope of $A C_{2}$ measures the capital labor ratio in the second industry.

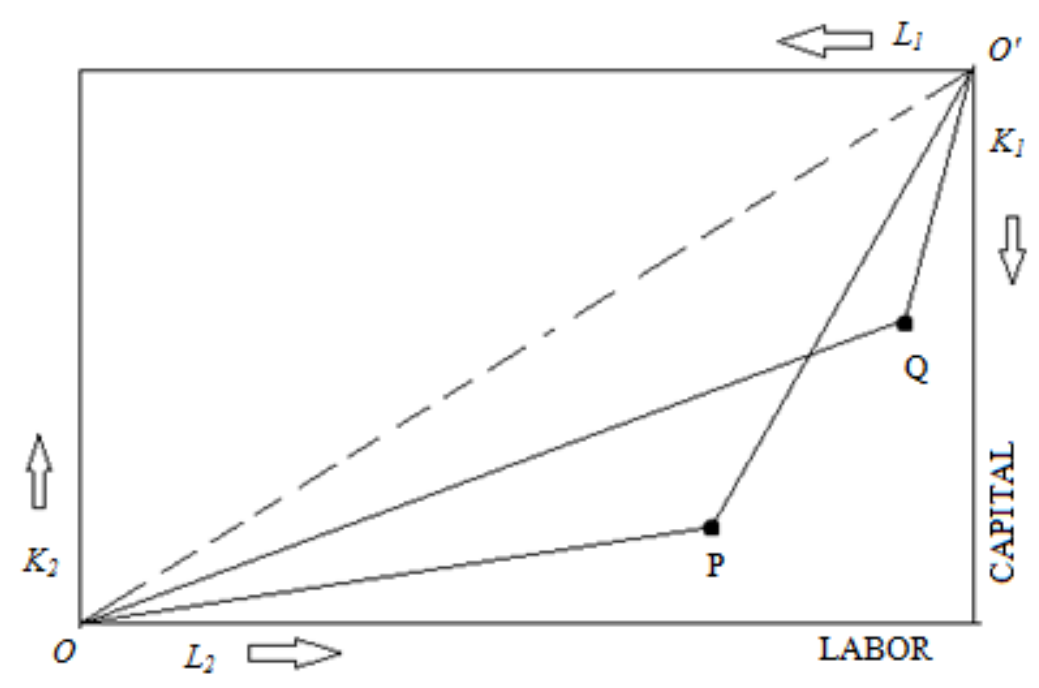

Figure 3. Structure of production

The length of the Edgeworth box measures the supply of labor and its height measures the supply of capital in the economy. The rays drawn from the upper right hand corner of the box represent output of the first industry and those drawn from the lower left hand corner represent output of the second industry. 


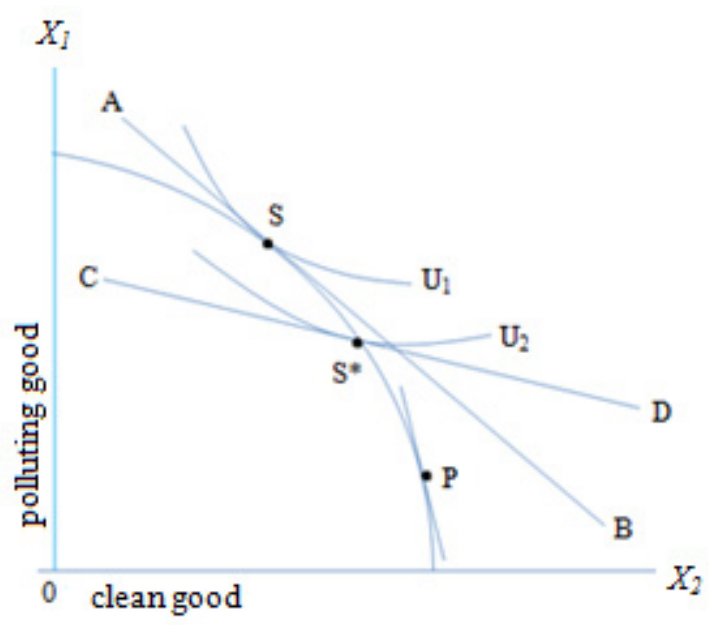

Figure 4. Autarky equilibrium

Point $\mathrm{S}$ is the autarky equilibrium point before cap-and-trade is implemented, showing equality between the marginal rate of transformation and the consumers' marginal rate of substitution (measured by the slope of the social indifference curve $\mathrm{U}_{1}$ ) between the two goods. The slope of line $A B$ represents the equilibrium terms of trade.

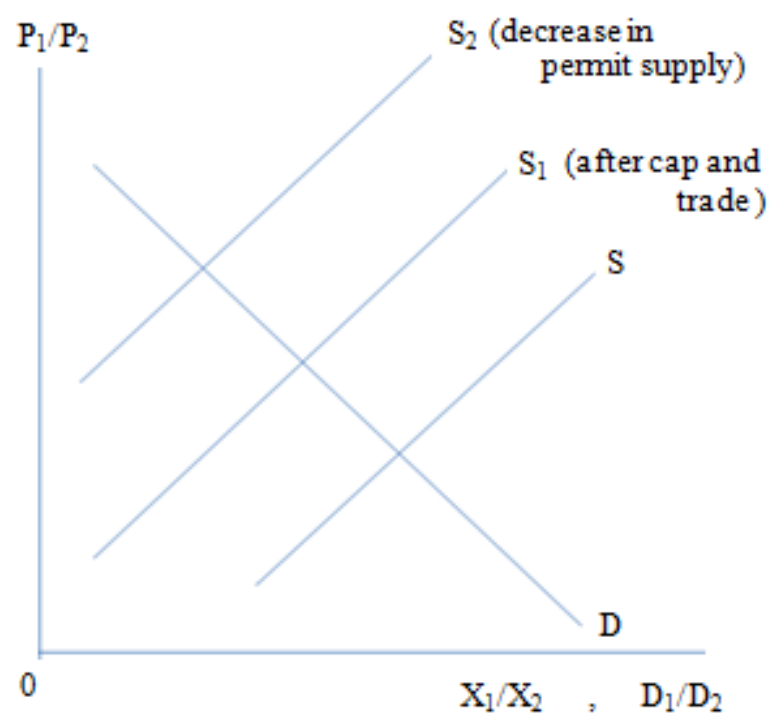

Figure 5. Autarky terms of trade

Initial equilibrium in the economy with the demand curve $\mathrm{D}$ and the supply curve $\mathrm{S}$. The introduction of Cap-and-trade shifts the supply curve to the left $\left(S_{1}\right)$, showing a decrease in $X_{1} / X_{2}$ at constant terms of trade. This has the effect of shifting the price ratio in favor the polluting good. A decrease in the number of permits issued would further reduce the relative supply of the polluting good $\left(\mathrm{S}_{2}\right)$ and raise its relative price. 


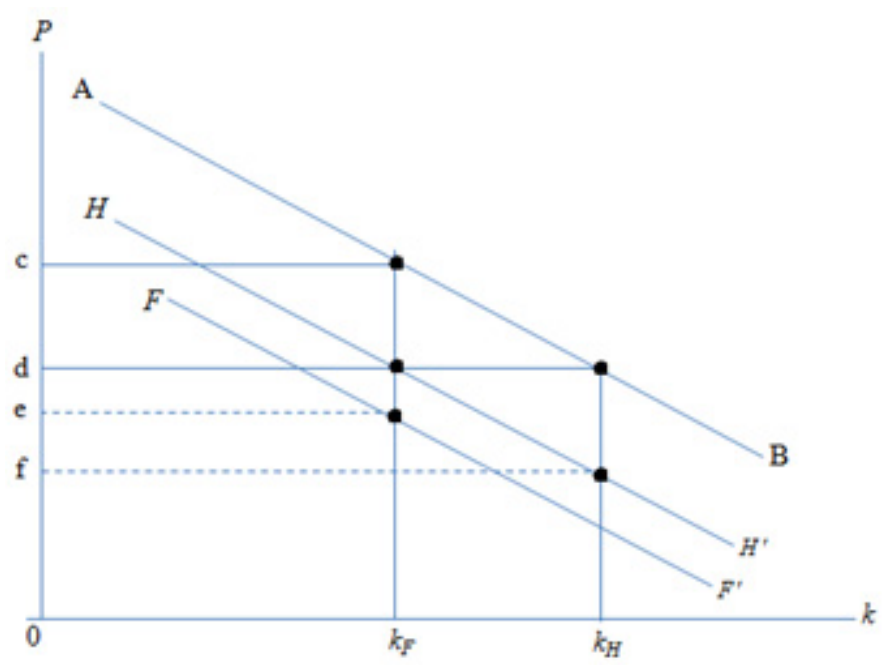

Figure 6. Pollution haven

This figure illustrates the relationship between $\mathrm{k}$ (the ratio of the supply of capital to the supply of labor) and $P$ ( the relative price of the pollution intensive good).

\section{Appendix}

Letting an asterisk denote the rate of change in a variable $\left(\mathrm{X}^{*}=\mathrm{dX} / \mathrm{X}\right)$, the total differentiation of equations (2.5) and (2.6) yields the following equations (assuming that unit costs are minimized at given factor prices):

$$
\begin{aligned}
& \theta_{L 1} w^{*}+\theta_{K 1} r^{*}=P_{1}^{\prime *} \\
& \theta_{L 2} w^{*}+\theta_{K 2} r^{*}=P_{2}^{\prime *}
\end{aligned}
$$

Here, $\theta_{L j} \equiv w C_{L j} / P_{j}^{\prime}$ and $\theta_{K j} \equiv r C_{K j} / P_{j}^{\prime}$ are respectively of shares of labor and capital in total revenue,

resulting in $\theta_{L j}+\theta_{K j}=1,(j=1,2)$. For the clean industry, total revenue includes the income from sale of emission permits and for the polluting industry, the total revenue is the net revenue after subtracting the cost of permits. The determinant $|\theta|$ in the set of two equations in (A.1) and (A.2) is:

$$
|\theta|=\theta_{L 1} \theta_{K 2}-\theta_{L 2} \theta_{K 1}=\frac{w r}{P_{1}^{\prime} P_{2}^{\prime}} C_{L 1} C_{L 2}\left(k_{2}-k_{1}\right)
$$

Here, $k_{1}$ and $k_{2}$ are respectively the capital/labor ratios in the two industries. Also, since the factor shares add to one, the result is: $|\theta|=\theta_{L 1}-\theta_{L 2}=\theta_{K 2}-\theta_{L 2}$. The sign of $|\theta|$ is the same as the sign of $\left(k_{2}-k_{1}\right)$. Factor price frontiers in figure 1 are derived from (A.1) and (A.2) after allowing $P_{j}^{\prime *}=0$. Using the definitions of $\theta_{i j}$, we find:

$$
\frac{d w}{d r}=-\frac{C_{K j}}{C_{L j}}=-k_{j} .
$$

The cost minimizing values of the input output coefficients are determined by minimizing $w C_{L j}+r C_{K j}$. Totally differentiating this expression at given factor prices: 


$$
\theta_{L j} C_{L j}^{*}+\theta_{K j} C_{K j}^{*}=0
$$

From the definition of the elasticity of substitution between labor and capital $\left(\sigma_{j}\right)$ the following equation is derived:

$$
-C_{L j}^{*}+C_{K j}^{*}=\sigma_{j}\left(w^{*}-r^{*}\right)
$$

Solving (A.3) and (A.4) and applying the properties of $|\theta|$, we obtain:

$$
\begin{aligned}
& C_{L j}^{*}=-\sigma_{j} \theta_{K j}\left(w^{*}-r\right) \\
& C_{K j}^{*}=\sigma_{j} \theta_{L j}\left(w^{*}-r\right)
\end{aligned}
$$

Totally differentiating (2.1) and (2.2),

$$
\begin{gathered}
P_{1}^{\prime *}=\lambda_{1} P_{1}^{*}+\lambda_{2} \bar{R}^{*}-\lambda_{3}\left(\rho_{1} \rho_{1}^{*}-s_{1} s_{1}^{*}\right) \\
P_{2}^{\prime^{*}}=\delta_{1} P_{1}^{*}+\delta_{2} s_{2}^{*}-\delta_{3} \bar{R}^{*} \\
\lambda_{1} \equiv\left[1-\beta\left(\rho_{1}-s_{1}\right)\right] \frac{P_{1}}{P_{1}^{\prime}} ; \quad \lambda_{2} \equiv \frac{\gamma\left(\rho_{1}-s_{1}\right)}{P_{1}^{\prime}} \bar{R}>0 ; \quad \lambda_{3} \equiv \frac{P_{R}^{e}}{P_{1}^{\prime}}>0 ; \\
\delta_{1} \equiv \beta_{2} \frac{P_{1}}{P_{2}^{\prime}}>0 ; \quad \delta_{2} \equiv \frac{s_{2} P_{R}^{e}}{P_{2}^{\prime}}>0 ; \quad \delta_{3} \equiv \frac{\gamma \bar{R}}{P_{2}^{\prime}}>0
\end{gathered}
$$

Subtracting (A.2) from (A.1) and applying the properties of the determinant $|\theta|$, we get (A.7) and (A.8).

$$
\omega^{*} \equiv w^{*}-r^{*}=\frac{1}{|\theta|}\left[\left(\lambda_{1}-\delta_{1}\right) P_{1}^{*}+\left(\lambda_{2}+\delta_{3}\right) \bar{R}^{*}-\lambda_{3} \rho_{1} \rho_{1}^{*}+\left(\lambda_{3} s_{1} s_{1}^{*}-\delta_{2} s_{2}^{*}\right)\right]
$$

A decrease in the number of permits issued $\left(\bar{R}^{*}<0\right)$, at constant terms of trade, would raise the wage rental ratio $\left(\omega^{*}>0\right)$, provided that the first industry is capital intensive $(|\theta|<0)$. This is shown in figure 1. (A.9) also shows that the wage rental ratio would increase if any one of the following parameters changes: pollution intensity increases $\left(\rho_{1}^{*}>0\right)$, the proportion of permits allocated to the polluting industry decreases $\left(s_{1}^{*}<0\right)$, and the proportion of permits allocated to the clean industry increases $\left(s_{2}^{*}>0\right)$.

Totally differentiating the full employment equations in (2.8) and (2.9),

$$
\begin{gathered}
\lambda_{L 1} X_{1}^{*}+\lambda_{L 2} X_{2}^{*}=L^{*}-\left(\lambda_{L 1} C_{L 1}^{*}+\lambda_{L 2} C_{L 2}^{*}\right) \\
\lambda_{K 1} X_{1}^{*}+\lambda_{K 2} X_{2}^{*}=K^{*}-\left(\lambda_{K 1} C_{K 1}^{*}+\lambda_{K 2} C_{K 2}^{*}\right)
\end{gathered}
$$

Here, $\lambda_{L j} \equiv C_{L j} X_{j} / L$ and $\lambda_{K j} \equiv C_{K j} X_{j} / K$ are respectively the proportion of labor force and endowment of capital used in industry $j(j=1,2)$. Therefore, $\lambda_{L 1}+\lambda_{L 2}=\lambda_{K 1}+\lambda_{K 2}=1$. The determinant of the system of two 
equations above is written as $|\lambda|$. Since input proportions add up to unity,

$|\lambda|=\lambda_{L 1}-\lambda_{K 1}=\lambda_{K 2}-\lambda_{L 2}=\frac{X_{1} X_{2}}{L K} C_{L 1} C_{L 2}\left(k_{2}-k_{1}\right)$. Subtracting (A.11) from (A.10), using the properties of

$|\lambda|$ and (A.5) through (A.9),

$$
X_{1}^{*}-X_{2}^{*}=\frac{L^{*}-K^{*}}{|\lambda|}+\frac{\beta_{L}+\beta_{K}}{|\lambda||\theta|}\left[\left(\lambda_{1}-\delta_{1}\right) P_{1}^{*}+\left(\lambda_{2}+\delta_{2}\right) \bar{R}^{*}-\lambda_{3} \rho_{1} \rho_{1}^{*}+\left(\lambda_{3} s_{1} s_{1}^{*}-\delta_{2} s_{2}^{*}\right)\right]
$$

$\left(\beta_{L} \equiv \lambda_{L 1} \sigma_{1} \theta_{K 1}+\lambda_{L 2} \sigma_{2} \theta_{K 2}>0\right)$

$\left(\beta_{K} \equiv \lambda_{K 1} \sigma_{1} \theta_{L 1}+\lambda_{K 2} \sigma_{2} \theta_{L 2}>0\right)$

A positive relationship between $X_{1} / X_{2}$ and $P_{1} / P_{2}$ is the sufficient condition for a stable equilibrium. Since this would require that $\left(\lambda_{1}-\delta_{1}\right)>0$, then it also follows, $\lambda_{1}>0$ in (A.7).

With given factor endowments and commodity prices, a decrease in the number of permits issued $\left(\bar{R}^{*}<0\right)$ would reduce $X_{1} / X_{2}$, as the coefficient of $\bar{R}^{*}$ in (A.12) is positive irrespective of factor intensities of the two sectors $(|\lambda||\theta|>0)$. Before the introduction of the cap-and-trade system, $\lambda_{1}=\delta_{1}=1$ and (A.12) shows a positive relationship between $P_{1} / P_{2}$ and $X_{1} / X_{2}$ which is also independent of factor intensities. The effect of relative factor endowments on the structure of production is represented by the first term of (A.12) and this effect depends on factor intensities. If the polluting sector is capital intensive $(|\lambda|<0)$, then an increase in $L / K$ would reduce $X_{1} / X_{2}$.

A logarithmic differentiation of equation (2.11) yields the following:

$$
D_{1}^{*}-D_{2}^{*}=\sigma_{D}\left(P_{2}^{*}-P_{1}^{*}\right)-\alpha \sigma_{D} \mu^{*}
$$

In autarky equilibrium, $D_{1} / D_{2}=X_{1} / X_{2} \Rightarrow D_{1}^{*}-D_{2}^{*}=X_{1}^{*}-X_{2}^{*}$. Therefore, from equations (A.12) and (A.13) it follows:

$$
\left(\sigma_{D}+\delta_{1} \sigma_{S}\right)\left(P_{2}^{*}-P_{1}^{*}\right)-\left(\lambda_{1}-\delta_{1}\right) P_{1}^{*}=\frac{L^{*}-K^{*}}{|\lambda|}+\sigma_{S}\left(\lambda_{2}+\delta_{3}\right) \bar{R}^{*}-\sigma_{S} \lambda_{3} \rho_{1} \rho_{1}^{*}+\sigma_{S}\left(\lambda_{3} s_{1} s_{1}^{*}-\delta_{3} s_{2}^{*}\right)+\alpha \sigma_{D} \mu^{*}
$$

Here $\sigma_{S} \equiv \frac{\beta_{L}+\beta_{K}}{|\lambda||\theta|}>0$, represents the elasticity of substitution on the supply side. The left hand side of (A.14) may be simplified now because $P_{2}^{*}=0$, by choice of numéraire. Let $P \equiv P_{1} / P_{2}$ be the relative price of the polluting good. Then it follows from (A.14):

$P^{*}=\frac{K^{*}-L^{*}}{\left[\sigma_{D}+\left(\lambda_{1}-\delta_{1}\right) \sigma_{S}\right]|\lambda|}-\frac{\sigma_{s}}{\left[\sigma_{D}+\left(\lambda_{1}-\delta_{1}\right) \sigma_{S}\right]}\left[\left(\lambda_{2}+\delta_{3}\right) \bar{R}^{*}-\lambda_{3} \rho_{1} \rho_{1}^{*}+\left(\lambda_{3} s_{1} s_{1}^{*}-\delta_{2} s_{2}^{*}\right)\right]-\frac{\alpha \sigma_{D}}{\sigma_{D}+\left(\lambda_{1}-\delta_{1}\right) \sigma_{S}} \mu^{*}$ 
The first term on the right hand side of (A.15) represents the Hechscher-Ohlin effect of relative factor endowment on terms of trade and the rest of the terms are related to the effect of different aspects of cap-and-trade on terms of trade. 